\title{
EDUCAR PARA A CIDADANIA NOS DISPOSITIVOS LEGAIS PARA A EDUCAÇÃO BÁSICA
}

Janieli Lopes Ferreira https://orcid.org/0000-0001-8859-1818

Selma Barros Daltro de Castro https://orcid.org/0000-0003-1655-8896

Ivonete Barreto de Amorim https://orcid.org/0000-0001-9943-2118

Luciana Rios da Silva https://orcid.org/0000-0003-3831-7399

\begin{abstract}
Universidade do Estado da Bahia- Campus XI- Serrinha Universidade do Estado da Bahia- Campus XI- Serrinha Universidade do Estado da Bahia- Campus XI- Serrinha Universidade Estadual de Feira de Santana
\end{abstract}

\begin{abstract}
Resumo: Os documentos oficiais e diretrizes que norteiam as políticas voltadas para a Educação Básica no Brasil apresentam aspectos relevantes sobre educar para a cidadania. Nesse sentido, o presente artigo objetiva analisar a abordagem da relação entre educação para a cidadania nos documentos oficiais da Educação Básica. Como subsídios teóricos foram utilizados Candau (2016), Libâneo (2006) Santos (2007) e Tonet (2005). Tratou-se de uma pesquisa de abordagem qualitativa e cunho bibliográfico, com análise dos documentos legais oficiais. Os resultados apontam que a Constituição Federal é documento orientador para os demais dispositivos legais que regulamentam a Educação Básica no Brasil, apresentando a escola como lugar para formação e exercício pleno da cidadania. Para compreender os desdobramentos dessa relação na prática das instituições de ensino, faz-se necessário empreender novos estudos a partir da análise dos documentos internos da escola, a exemplo do Projeto Político Pedagógico (PPP), plano de curso, projetos institucionais e, sobretudo, analisar as relações sociais entre os sujeitos que dão vida à escola.
\end{abstract}

Palavras-chave: Educação. Cidadania. Documentos oficiais.

\section{EDUCATE FOR CITIZENRY IN LEGAL ARRANGMENTS FOR BASIC EDUCATION}

\begin{abstract}
The official documents and guidelines that guide policies aimed at Basic Education in Brazil present relevant aspects about educating for citizenry. Therefore, this article aims to analyse the approach to the relationship between education for citizenry in the official documents of Basic Education. Theoretical subsidies were supported by Candau (2016), Libâneo (2006) Santos (2007) and Tonet (2005). This work was based on qualitative and bibliographic research, analysing the official legal documents. The results show that the Federal Constitution is a guiding document for the other legal provisions that regulate Basic Education in Brazil, presenting the school as a place for the formation and full exercise of citizenship. In order to understand the consequences of this relationship in the practice of educational institutions, it is necessary to undertake new studies based on the analysis of the school's internal documents, such as the Pedagogical Political Project (PPP), course plan, institutional projects and, above all, social relations between the subjects that give life to the school.
\end{abstract}

Key words: Education. Citizenry. Official documents.

Como citar o artigo: FERREIRA, J.L, CASTRO; S.D; AMORIM, I. B; SILVA, L.R. Educar para a cidadania nos dispositivos legais para a educação básica. Revista Científica Novas Configurações-Diálogos Plurais, v.2, n.1, 2021.

Fonte de financiamento: Nenhum

Conflito de interesse: Os autores declaram não haver Nenhum conflito de interesse.

E-mail do autor-correspondência: janieli.ferreira1@enova.educacao.ba.gov.br

Data de recebido: 17/10/2020

Data de aprovado: 01/12/2020

Editora: Elisângela Maura Catarino 


\section{INTRODUÇÃO}

Muitos são os aspectos relacionados ao educar para a cidadania no âmbito dos documentos oficiais e diretrizes que norteiam as políticas voltadas para a Educação Básica, contudo frente a um cenário cada vez mais conservador e marcado pela perda de direitos historicamente assegurados, faz-se necessário analisar como a relação entre educação e/para a cidadania é abordada nos documentos oficiais que orientam a Educação Básica, uma vez que o conceito em questão deve avançar para além da visão limitada de que a cidadania configura-se como o direito a ter direitos e/ou direitos e deveres dos cidadãos.

Para ampliar o conceito de cidadania é fundamental a compreensão enquanto prática social, que precisa ser reforçada como tal, para que o sujeito possa transitar com segurança em todos os âmbitos de uma sociedade. A escola, embora não seja o único espaço de formação cidadã, tem um papel muito importante na trajetória formativa dos sujeitos que a compõe, no entanto, é pertinente destacar que no contexto contemporâneo são recorrentes os movimentos conservadores e opressores que tentam influenciar as políticas voltadas para a educação nacional, segregando as camadas menos favorecidas socialmente.

O contexto conservador/opressor, marcado pela retirada de direitos, a exclusão imposta aos coletivos sociais mais segregados (negros, índios, mulheres, comunidades formadas por pessoas lésbicas, gays, bissexuais, travestis, transexuais e transgêneros - LGBT, entre outros) tem sido uma prática cada vez mais naturalizada. Se o papel social da escola é o de educar para a cidadania, o acolhimento e o respeito à diversidade historicamente segregada através das práticas colonizadoras institucionalizadas por meio do currículo escolar, o trabalho em questão ganha justificativa e relevância acadêmica por entender a necessidade de empreender uma discussão com vistas a reflexão sobre o educar para a cidadania.

Nesse sentido, o objetivo acerca do qual essa produção se debruça consiste em refletir sobre a abordagem dada ao conceito de educar para a cidadania presente em documentos oficias que versam sobre Educação Básica. Para tanto, propõe uma análise a respeito da Cidadania expressa em marcos legais que norteiam o processo educacional brasileiro, a exemplo da Constituição Federal de 1988, a Lei de Diretrizes e Bases da Educação Nacional (LDBN No 9394/1996), as Diretrizes Curriculares Nacionais para a Educação Básica, além da Base Nacional Comum Curricular-BNCC.

Trata-se de uma pesquisa de abordagem qualitativa e cunho bibliográfico, que utilizou como lastro teórico, além dos documentos oficiais supracitados, as produções de Candau (2016), Libâneo (2006) Santos (2007) e Tonet (2005). O artigo é delineado em quatro seções, além da introdução e considerações finais.

\section{A CIDADANIA EXPRESSA NA CONSTITUIÇÃO FEDERAL DE 1988}

O período que compreendeu a ditadura militar no Brasil foi marcado pelo cerceamento de direitos civis e políticos, teoricamente retomados a partir do processo de redemocratização da sociedade brasileira e, consequentemente, através da promulgação da Constituição Federal, em 05 de outubro de 1998, cujas questões relativas à cidadania começaram a emergir.

Conhecida como Constituição Cidadã, a promulgação da Constituição Federal (CF) de 1988 corroborou para que os direitos dos sujeitos fossem pensados a partir das dimensões civis, políticas, sociais e culturais, e apresenta em seu artigo primeiro um dos princípios fundamentais: 
Art. $1^{\circ}$ A República Federativa do Brasil, formada pela união indissolúvel dos Estados e Municípios e do Distrito Federal, constitui-se em Estado democrático de direito e tem como fundamentos:

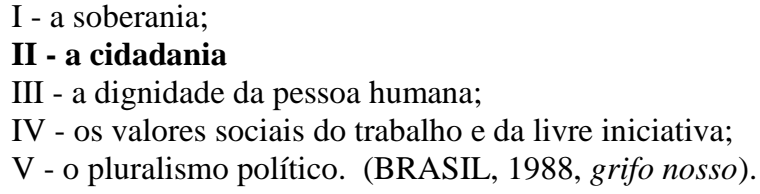

Ainda de acordo com a CF de 1988, a formação dos sujeitos para o exercício da cidadania é de responsabilidade do Estado e da família, cabendo a essas instituições prepararem os sujeitos desde a mais tenra idade para a consolidação do exercício da cidadania, responsabilidade prioritária que deve ser incentivada ainda por outras instâncias sociais.

Embora a CF vigente tenha assegurado condições indispensáveis ao exercício da cidadania (como igualdade perante a lei, liberdade de ir e vir, direito à saúde, educação, trabalho, moradia, entre outras questões inerentes ao ser cidadão), Santos (2007) pondera que a cidadania registrada na Constituição Federal está muito aquém de atingir plenamente os sujeitos. Como exemplo, o autor pontua que, mesmo sendo uma das prerrogativas da cidadania assegurada pela Constituição, os direitos trabalhistas têm sido precarizados e ocasionam impactos irreparáveis à cidadania dos sujeitos, seja através da retirada de direitos, seja através da ausência de um trabalho digno, demarcado por uma ocupação precária e mal remunerada. Outra questão passível de reflexão apontada por Santos (2007) diz respeito à grande desinformação jurídica dos sujeitos, fato que, segundo o autor, corrobora para que um número insignificante desses sujeitos se dê conta de que direitos historicamente assegurados estão lhe sendo cerceados. Para arrematar a questão suscitada, o autor ainda nos indaga se tal situação reflete apenas desinformação ou se está relacionada à certeza de que não adiantar reclamar, demonstrando, desta forma, a ausência do sujeito questionador.

Face ao exposto, nos cabe ponderar qual tipo de educação estamos proporcionando para a emancipação de sujeitos críticos, conscientes e capazes de questionar? Em que medida o processo educacional ao qual são submetidos corrobora para que os sujeitos se apropriem de um arcabouço jurídico que lhes possibilite conhecer os documentos que versam sobre seus direitos? De que forma os sujeitos percebem a necessidade de se posicionar diante de uma sociedade que embora, defina-se como igualitária, conserva e reproduz a desigualdade, classificando as pessoas a partir do capital ${ }^{1}$ acumulado?

Portanto, ao consideramos a necessidade de educar para a cidadania, a seção a seguir buscou tecer reflexão acerca do que preconiza a Lei de Diretrizes e Bases da Educação Nacional LDBN N 9394/1996 no tocante à educação para a cidadania.

\section{A LEI DE DIRETRIZES E BASES DA EDUCAÇÃO NACIONAL LDBN N 9394/1996 NO TOCANTE A EDUCAÇÃO E/OU PARA A CIDADANIA}

Nesta seção, o objetivo foi sistematizar os princípios que versam sobre a relação entre educação e cidadania apontadas pela LDB 9394/1996. Para tanto, cabe destacar que esse marco legal aponta como uma das finalidades da educação básica a garantia ao estudante de uma formação indispensável ao exercício da cidadania, conforme explicitado no artigo 22:

\footnotetext{
${ }^{1}$ Capital aqui empregado no sentido da teoria de Bourdieu (1989), representado como o acúmulo de forças que o indivíduo pode alcançar no
} campo, representado através das vantagens culturais mobilizadas e que, de modo geral, conduzem a um nível socioeconômico mais elevado. 
A educação básica tem por finalidades desenvolver o educando, assegurar-lhe a formação comum indispensável para o exercício da cidadania e fornecer-lhe meios para progredir no trabalho e em estudos posteriores (BRASIL, 1996, grifo nosso).

Partindo desse princípio, pode-se inferir que a educação básica tem um papel social importante no que tange a corroborar com/para a formação necessária ao exercício da cidadania. Para transitar com segurança nas mais variadas esferas da nossa sociedade, é importante que os sujeitos estejam preparados no viés crítico de formação humana, no âmbito de um currículo em que a cidadania ocupe espaço privilegiado, transversal e interdisciplinar, não só nos componentes educativos, mas que perpasse, sobretudo, pelas relações sociais entre os sujeitos que compõem a escola.

Apesar do que explicita o artigo 22 da LDB 9394/1996, no que concerne à cidadania, Candau (2016) aponta caminhos passíveis de reflexões acerca da quantidade de avaliações de larga escala, a que é submetido o nosso sistema educacional, cuja função é mensurar o desempenho acadêmico dos estudantes em determinados componentes curriculares. Como consequência da preocupação em medir resultados quantitativos em detrimento dos resultados qualitativos, questões relacionadas ao formar para a cidadania acaba, por vezes, ocupando espaço menos privilegiado no currículo escolar.

O excesso de avaliações em larga escala não é um fator positivo ao considerar-se o pressuposto de que a educação tem como papel fundamental a formação para o exercício da cidadania. Segundo Candau (2016), essa grande quantidade de testes e avaliações aos quais os estudantes são submetidos condiciona o processo educacional basicamente a um ensino de alguns conhecimentos específicos. Nesse sentido, educar se reduz a ensinar. Ensinar a instruir. Instruir a preparar para ter êxito em testes padronizados, movimento que resume a educação a questões meramente operacionais (CANDAU, 2016).

A partir da reflexão suscitada pela autora, pode-se perceber que a preocupação com dados quantitativos mensurados através das avaliações em larga escala, que recaem sobre o nosso sistema educacional, é um indicador que questiona a finalidade da educação básica em formar para o exercício da cidadania, preconizada pela legislação aqui em questão. Preparar e instruir sujeitos para o êxito em avaliações padronizadas instrumentaliza a educação para as questões operacionais que não asseguram uma formação cuja finalidade seja o exercício da cidadania, destacada no marco legal.

Nesse contexto, formar para o exercício da cidadania, como preconiza a LDB 9394/1996, é uma tarefa complexa que necessita ser ressignificada, uma vez que, como aponta Tonet (2005), a contribuição da educação é na construção de uma sociedade cada vez mais livre e humana,

Quer dizer, uma educação que contribua para formar os indivíduos como cidadãos e cidadãos críticos, isto é, indivíduos que participam ativamente do processo social. Isto supõe ampliar cada vez mais o acesso de todos à educação; garantir um nível cada vez mais elevado de acesso ao saber, o que implica melhorar as condições gerais de trabalho de todos os envolvidos no processo; buscar métodos democráticos e ativos de ensino-aprendizagem; estabelecer uma interação ativa entre a escola e a comunidade; estabelecer formas democráticas e participativas tanto na gestão da escola quanto na elaboração da política educacional mais geral etc. Em resumo, construindo experiências de educação democrática, participativa, autônoma e sintonizada com os interesses das classes populares (TONET, 2005 p.473). 
Deste modo, uma formação para o exercício da cidadania transcende o que está posto na legislação aqui em questão, pois envolve um projeto político de educação emancipatória e democrática, que seja pensado a partir dos interesses das camadas populares e, sobretudo, de forma coletiva com/para os que mais necessitam lutar para garantir espaços de poder no cenário social que cada vez mais tem se apresentado como opressor e marcado pela desigualdade social.

A seguir, serão apresentadas reflexões sobre os princípios de cidadania e sua relação com a educação, sistematizados nas Diretrizes Curriculares Nacionais para a Educação Básica-DCN.

\section{CIDADANIA E EDUCAÇÃO NAS DIRETRIZES CURRICULARES NACIONAIS PARA A EDUCAÇÃO BÁSICA}

As Diretrizes Curriculares Nacionais para a Educação Básica (DCN) constituem-se como um conjunto de definições doutrinárias sobre princípios, fundamentos e procedimentos na Educação Básica, que servem para nortear as instituições escolares na organização, desenvolvimento, articulação e avaliação das propostas pedagógicas a serem pensadas por cada instituição.

Dentre os principais objetivos das Diretrizes está o de

Sistematizar os princípios e diretrizes gerais da Educação Básica contidos na Constituição, na LDB e demais dispositivos legais, traduzindo-os em orientações que contribuam para assegurar a formação básica comum nacional, tendo como foco os sujeitos que dão vida ao currículo e à escola" (BRASIL, 2013 p.07).

Tal documento está ancorado no direito da pessoa ao seu pleno desenvolvimento, à preparação para o exercício da cidadania e à qualificação para o trabalho, estando de acordo com o seu objetivo de sistematizar os princípios que estão postos, tanto na Constituição, quanto na LDB, além de apontar para a necessidade de atualizações das políticas educacionais no que concerne ao direito à formação humana, cidadã e profissional, conforme explicitado:

A necessidade de definição de Diretrizes Curriculares Nacionais Gerais para a Educação Básica está posta pela emergência da atualização das políticas educacionais que consubstanciem o direito de todo brasileiro à formação humana e cidadã e à formação profissional, na vivência e convivência em ambiente educativo (BRASIL, 2013, p.07).

Face ao exposto, é notório que o documento aponta para a emergência em atualizar as políticas educacionais com vistas ao direito à formação humana, cidadã e profissional. Essa formação necessita ser assegurada nos contextos das instituições de educação básica do nosso país, uma vez que a preocupação com essa construção cidadã precisa se materializar nos espaços onde ocorrem os processos formativos, isto é, o chão das escolas. Nesse sentido, os sujeitos que a compõem precisam assumir o papel de cidadãos partícipes, críticos e conscientes da realidade a qual estão inseridos, pois "a educação é uma prática social que busca realizar nos sujeitos humanos as características de humanização plena" (LIBÂNEO, 2006, p.66).

Para enfatizar a abordagem quanto à cidadania e à educação presentes no documento aqui em questão, apontamos ainda alguns aspectos que estão presentes no corpo do próprio documento, julgados como importantes no que concerne à relação da educação com/para a cidadania:

A Educação Básica é direito universal e alicerce indispensável para a capacidade de exercer em plenitude o direto à cidadania. É o tempo, o espaço e o contexto em que o sujeito aprende a constituir e reconstituir a sua identidade, em meio a 
transformações corporais, afetivo emocionais, socioemocionais, cognitivas e socioculturais, respeitando e valorizando as diferenças. Liberdade e pluralidade tornam-se, portanto, exigências do projeto educacional (BRASIL, 2013 p.17).

Ao refletirmos sobre o exposto, as Diretrizes são documentos com indicativas mandatórias para que os estabelecimentos de ensino tomem como base para planejar o trabalho pedagógico fundamentado na cidadania e nos princípios democráticos. As ações planejadas a partir das diretrizes precisam proporcionar reflexão crítica através dos princípios sociais e constitucionais, de liberdade, pluralidade, valorização das diferenças e, sobretudo, ter como premissa um projeto educacional de direito universal que aborde como princípio fundamental a formação humana para o exercício pleno da cidadania. Para tanto, é indispensável assegurar outros direitos também explicitados nas prerrogativas legais, conforme o exposto:

\begin{abstract}
A aquisição plena desse direito depende da possibilidade de exercitar todos os demais direitos, definidos na Constituição, na ECA, na legislação ordinária e nas inúmeras disposições legais que consagram as prerrogativas do cidadão brasileiro. Somente um ser educado terá condição efetiva de participação social, ciente e consciente de seus direitos e deveres civis, sociais, políticos, econômicos e éticos (BRASIL, 2013, p.17).
\end{abstract}

Portanto, assegurar a universalização da educação básica, tendo em vista uma formação para o exercício pleno da cidadania, perpassa pela necessidade de assegurar os direitos que em tese constituem as prerrogativas do cidadão brasileiro. Significa assegurar uma educação de qualidade com vistas à formação humana, que dê condições para que os sujeitos participem ativamente em seu meio social, de forma consciente e ciente dos seus direitos e deveres não só civis, mas sociais, políticos, econômicos e éticos como apontam as diretrizes.

Diante do que foi discutido até aqui, ao considerarmos que a Base Nacional Comum Curricular é um dos documentos norteadores da educação mais recente, julga-se necessário refletir sobre os aspectos que relacionam educação e/para a cidadania presente no documento em questão, na seção seguinte.

\title{
5 EDUCAÇÃO E/PARA A CIDADANIA NO CONTEXTO DA BASE NACIONAL COMUM CURRICULAR-BNCC
}

Com base em seu capítulo introdutório, a Base Nacional Comum Curricular (BNCC) é um documento de caráter normativo com vistas à definição de um o conjunto de aprendizagens essenciais que todos os estudantes devem desenvolver ao longo das etapas e modalidades da Educação Básica, de modo que tenham assegurados seus direitos de aprendizagem e desenvolvimento.

Foi elaborado em conformidade com o que está posto na Constituição Federal de 1988, na Lei de Diretrizes e Bases da Educação Nacional Lei 9394/1996, no Plano Nacional de Educação (PNE-2014) e está orientado pelos princípios éticos, políticos e estéticos que visam a formação humana integral e a construção de uma sociedade justa, democrática e inclusiva, como fundamentado nas Diretrizes Curriculares Nacionais da Educação Básica (DCN). Todos esses documentos apontam para a uma educação capaz de promover o desenvolvimento integral dos estudantes e a sua preparação para a vida, para o trabalho e para o exercício da cidadania.

Durante a trajetória da Educação Básica, as aprendizagens essenciais definidas pela BNCC têm como finalidade assegurar aos estudantes o desenvolvimento de dez competências gerais definidas pelo documento, como a mobilização de conhecimentos (conceitos e procedimentos), habilidades (práticas, cognitivas e 
socioemocionais), atitudes e valores, para resolver demandas complexas da vida cotidiana, do pleno exercício da cidadania e do mundo do trabalho (BRASIL, 2017).

As competências gerais também se orientam por estudos e tendências sobre o que os estudantes precisam aprender para lidar com os desafios do mundo contemporâneo, caracterizado por intensas mudanças, cujos reflexos impactam diretamente no contexto escolar que, por sua vez, foi constituído através de um modelo em que as mudanças ocorriam de forma menos acelerada e pareciam não afetar o nosso sistema educacional como um todo.

No que tange à relação entre Educação e/para a cidadania, entre as dez competências gerais da Educação Básica, está a responsabilidade e cidadania, baseadas no agir pessoal e coletivo, com autonomia, responsabilidade, flexibilidade, resiliência e determinação, tomando decisões com base em princípios éticos, democráticos, inclusivos, sustentáveis e solidários. A proposta é desenvolver na criança e no jovem a consciência de que eles podem ser agentes transformadores na construção de uma sociedade mais democrática, justa, solidária e sustentável. Além disso, traz a necessidade de valorizar a diversidade de saberes e vivências culturais e apropriar-se de conhecimentos e experiências que lhes possibilitem entender as relações próprias do mundo do trabalho, fazer escolhas alinhadas ao exercício da cidadania e ao seu projeto de vida, com liberdade, autonomia, consciência crítica e responsabilidade (BRASIL, 2017).

Nesse sentido, a BNCC aponta competências a serem desenvolvidas com base nos princípios éticos, inclusivos e democráticos, visando colocar as crianças e os jovens como protagonistas na construção de uma sociedade mais justa e solidária, além de pautar suas escolhas alinhadas ao exercício da cidadania e ao seu projeto de vida. Contudo, apesar de considerar o que está posto nas Diretrizes em relação à construção de uma sociedade justa, democrática e inclusiva, questões importantes e pertinentes a esse modelo de sociedade foram suprimidas pelo documento em questão, a exemplo da perspectiva de gênero.

Não se pode falar em educar para a cidadania, tampouco em escola inclusiva e democrática, quando o próprio documento que deveria reafirmar a existência da diversidade de gênero para além do modelo binário historicamente construído elimina questões sem as quais não se educa para a cidadania. Urge repensar o ato de educar cidadãos através de práticas pedagógicas orientadas por um documento que segrega, à medida que todos aqueles sujeitos que fogem dos padrões institucionalizados como o modelo socialmente aceitos são tratados com indiferença, e perdem espaço na agenda de discussões sobre documentos norteadores do currículo.

Outro elemento ponderado pela BNCC, e pertinente a ser destacado, diz respeito ao ensino religioso, previsto pela Constituição Federal de 1988 e na LDB de 1996, de forma facultativa aos estudantes do ensino fundamental. Para tal reflexão, é importante tomar como base algumas competências presentes na RESOLUÇÃO CNE/CP Nº 2, DE 22 DE DEZEMBRO DE 2017, que institui e orienta a implantação da Base Nacional Comum Curricular:

Compreender, valorizar e respeitar as manifestações religiosas e filosofias de vida, suas experiências e saberes, em diferentes tempos, espaços e territórios; [...] Conviver com a diversidade de identidades, crenças, pensamentos, convicções, modos de ser e viver... [...] Debater, problematizar e posicionar-se frente aos discursos e práticas de intolerância, discriminação e violência de cunho religioso, de modo que se assegure assim os direitos humanos no constante exercício da cidadania e da cultura de paz. (BRASIL, 2017)

$\mathrm{O}$ documento norteador defende o respeito à diversidade religiosa, de modo a assegurar os direitos humanos no constante exercício da cidadania e da cultura de paz. Contudo, o Supremo Tribunal Federal (STF), mais alta instância do poder judiciário brasileiro, em decisão anunciada em 27 de setembro de 2017, 
autorizou o ensino religioso de caráter confessional nas escolas públicas, ou seja, as escolas podem tratar de conteúdos voltados para uma religião específica. Essa decisão suscita reflexão no tocante ao fato de que, mesmo sendo de matrícula facultativa para o aluno, vai de encontro aos princípios de laicidade do Estado preconizado pela nossa Constituição Federal, à medida que abre possibilidades para o trabalho com uma religião específica, em detrimento de outras.

Nessa perspectiva, ao considerarmos os altos índices de intolerância religiosa que circulam pelos principais veículos de comunicação do nosso país, sobretudo quando se trata das religiões de matrizes africanas em conjunto com a diversidade de religiões que podem representar os agentes que convivem nos estabelecimentos de ensino, a decisão do STF abre espaço para questionamentos acerca de que forma esse ensino se dará sem ferir os princípios da CF e, principalmente, os direitos dos cidadãos, inclusive de não serem adeptos de crenças religiosas.

Portanto, em tese, a BNCC busca superar antigos entraves que perpassam pela educação básica, na tentativa de responder aos novos desafios contemporâneos que se apresentam, no entanto, as revisões curriculares necessitarão ser acompanhadas por mudanças mais profundas no ambiente, nas práticas pedagógicas e, principalmente, na cultura dos professores e das instituições escolares para que, de fato, possamos ter uma educação mais inclusiva, justa e igualitária.

Para que nossos estudantes sejam formados numa ótica democrática, com vistas ao exercício pleno da cidadania e a transformação social em prol dos coletivos sociais marginalizados, é importante que sintam-se representados no currículo escolar, independente de sua classe social, cor, religião, orientação sexual ou qualquer outro fator determinante da exclusão social.

Essa construção não se constitui em uma tarefa fácil, tendo em vista os desafios encontrados no terreno legal do Brasil. Pensar um projeto de escola emancipatória em uma sociedade opressora e excludente, que suprime a discussão sobre diversidade de gênero em documento norteador da educação e que legitima através da mais alta instância do poder judiciário o caráter de ensino religioso confessional, revela um árduo caminhar em direção à consolidação de uma educação realmente justa, igualitária e que vislumbre a formação para a cidadania.

\section{CONSIDERAÇÕES FINAIS}

Essa produção buscou analisar como os documentos oficiais abordam a relação entre educação e/para a cidadania, contudo, para conhecer tal relação com maior afinco, é necessário analisar outras variáveis no âmbito das nossas instituições educacionais. Documentos como o Projeto Político Pedagógico das escolas, os planos de cursos, os projetos e, sobretudo, a teia de relações dos sujeitos que compõe esse ambiente tão plural e diverso, tornam-se de grande valia, uma vez que a formação da/para a cidadania perpassa pelo exercício ativo, crítico, consciente e, sobretudo, democrático.

Quando todos se integram em prol da qualidade do processo educativo, respeitando os dispositivos legais, os documentos da própria instituição e os instrumentos que configuram a práxis educativa, construir um projeto de educação que tenha como objetivo a emancipação dos sujeitos torna-se mais viável. Todavia, não podemos negar que no cenário neoliberal, o nosso sistema educacional, na maioria das vezes, está mais preocupado com as avaliações externas que buscam mensurar dados quantificáveis do processo em detrimento de uma formação para o exercício da cidadania. 
Para, além disso, é necessário superar algumas tradições curriculares fragmentadas e homogêneas, historicamente enraizadas, que visam a memorização de conceitos desarticulados do contexto social, político e cultural contemporâneo e, como consequência, limitam a maneira como o sujeito se posiciona diante da realidade social marcada pela desigualdade e exclusão.

Nesse contexto, ao considerarmos que a universalização da educação básica nem sempre chega a todos com a mesma qualidade, tampouco assegura uma educação para a cidadania, podemos facilmente perceber que haverá sempre direitos a serem conquistados, haverá minorias historicamente excluídas que precisam exercitar e usufruir de forma ativa, crítica e consciente da cidadania enquanto prática social de bem estar coletivo.

Cabe à escola elaborar sua proposta política pedagógica a partir de uma concepção de ensino enquanto instrumento de emancipação social dos sujeitos, não só assegurando o que está expresso nos documentos que norteiam a educação básica, mas, sobretudo, questionando-os sobre qual tipo de educação para a cidadania está sendo apresentada nas entrelinhas de cada documento.

Também cabe pensar a articulação teórico-prática de uma educação para a cidadania que seja justa, igualitária e democrática. Entretanto, ao nos reportarmos à exclusão de temáticas tão caras quanto as questões de gênero suprimidas na BNCC, por exemplo, urge questionar de que forma podemos ofertar uma educação para a cidadania, desconsiderando questões relacionadas aos coletivos sociais diversos que compõem as nossas instituições de ensino, que são representados através de gêneros e sexualidades para além do modo binário, e que precisam ser acolhedoras independentemente dos padrões socialmente aceitos.

Portanto, essa pesquisa abre espaço para serem empreendidas novas pesquisas à medida que, além de analisar o que os documentos legais sistematizam a partir da relação entre cidadania e educação, faz-se necessário compreender como tais conceitos dialogam nos documentos de cada instituição e como se materializam na prática de cada contexto, abrindo espaços para novos questionamentos acerca do que é educação. Muitas questões relevantes acerca do educar para a cidadania são facilmente levantadas, mas é emergente que pensemos sobre o que é ser cidadão no cenário contemporâneo para além dos direitos e deveres expressos na Constituição Federal, os quais nem sempre são assegurados.

\section{REFERÊNCIAS}

BOURDIEU, Pierre. O poder simbólico. Rio de Janeiro: Bertrand Brasil, 1989.

Brasil. Ministério da Educação. Secretaria de Educação Básica. Secretaria de Educação Continuada, Alfabetização, Diversidade e Inclusão. Conselho Nacional da Educação. Diretrizes Curriculares Nacionais Gerais da Educação Básica/ Ministério da Educação. Secretária de Educação Básica. Diretoria de Currículos e Educação Integral. - Brasília: MEC, SEB DICEI, 2013.Disponível em PDF: http://portal.mec.gov.br/docman/julho-2013-pdf/13677-diretrizes-educacao-basica-2013pdf/file. Acesso em dez. de 2019.

BRASIL. Congresso Nacional. Lei 9.394 de 20 de dezembro de 1996. Estabelece as diretrizes e bases da educação nacional. Diário Oficial da União, Brasília, DF, 23 dez. 1996. Disponível em:<http://www.planalto.gov.br/ccivil_03/Leis/L9394.htm>. Acesso em dez. 2019.

BRASIL. Constituição (1988). Constituição da República Federativa do Brasil. Brasília, DF: Senado Federal. Disponível em: https://www.jusbrasil.com.br/busca?q=constitui\%C3\%A7\%C3\%A3o+federal. Acesso em Dez de 2019.

BRASIL. Ministério da Educação. Base Comum Nacional Curricular. Brasília: MEC, 2017. Disponível em: http://basenacionalcomum.mec.gov.br/images/BNCC_EI_EF_110518_versaofinal_site.pdf. Acesso em dez. de 2019.

CANDAU, Vera Maria Ferrão. Cotidiano escolar e práticas interculturais.In.: Cadernos de Pesquisa v.46 n -161 p.802-820 $\mathrm{jul} / \mathrm{set} 2016$. 
LIBÂNEO, José Carlos. Ainda as perguntas: o que é pedagogia, quem é o pedagogo, o que deve ser o curso de Pedagogia. In: PIMENTA, Selma Garrido (org).Pedagogia e Pedagogos: caminhos e perspectivas. p. 59-97. 2 ed. - São Paulo: Cortez, 2006.

MINISTÉRIO DA EDUCAÇÃO CONSELHO NACIONAL DE EDUCAÇÃO CONSELHO PLENO RESOLUÇÃO CNE/CP N 2, DE 22 DE DEZEMBRO DE 2017. Institui e orienta a implantação da Base Nacional Comum Curricular, a ser respeitada obrigatoriamente ao longo das etapas e respectivas modalidades no âmbito da Educação Básica. Disponível em:http://basenacionalcomum.mec.gov.br/images/historico/RESOLUCAOCNE_CP222DEDEZEMBRODE2017.pdf.Acess o em dezembro de 2019.

SANTOS, Milton. O espaço do Cidadão. 7 ed.-São Paulo: Editora da Universidade de São Paulo, 2007.

TONET, Ivo. Educar para a cidadania ou para a liberdade? In.:Perspectivas, Florianópolis, v23, n02, p.469-484, jul.dez/2005. Disponível em PDF.

Informações sobre os autores:

JLF: Graduada em Licenciatura em Pedagogia pela Universidade do Estado da Bahia, Departamento de Educação Campus XI-Serrinha. Especialista em Inclusão e Diversidade na Educação pela Universidade Federal do Recôncavo da Bahia (UFRB). Membro do Grupo de Pesquisa Educação, Políticas Públicas e Desenvolvimento Social (EPODS). Coordenadora pedagógica efetiva da Rede Estadual de ensino da Bahia. E-mail: janieli.ferreira1@enova.educacao.ba.gov.br

SDC: Pós-Doutora em Educação pela Universidade Estadual de Feira de Santana (UEFS), Doutora e Mestre em Educação pelo Programa de Pós-Graduação em Educação da Universidade Federal da Bahia. Professora Adjunta Universidade do Estado da Bahia, Departamento de Educação Campus XI-Serrinha e professor do Programa de Mestrado Profissional em Intervenção Educativa e Social (MPIES), professora horista da Faculdade Anísio Teixeira, professor da Prefeitura de Feira de Santana. Vice-líder do grupo de pesquisa Educação, Políticas Públicas e Desenvolvimento Social (EPODS) - UNEB/CAMPUS XI e Membro do grupo de Pesquisa Núcleo de Estudos e Pesquisas sobre Formação do Professor (NUFOP/UEFS). E-mail: selmadaltro@gmail.com

IBA: Pós-Doutora em Educação e Contemporaneidade pelo PPGEduC/UNEB. Doutora em Família na Sociedade Contemporânea pelo Programa de Pós-graduação da Universidade Católica do Salvador - UCSAL. Professora Adjunta da Universidade do Estado da Bahia Campus XI. Professora, Orientadora e Vice Coordenadora do Mestrado Profissional em Intervenção Educativa e Social (MPIES). Líder do grupo de pesquisa Educação, Políticas Públicas e Desenvolvimento Social (EPODS) - UNEB/CAMPUS XI. E-mail: ivoneteeducadora623@gmail.com

LRS: Mestre em Educação e Contemporaneidade pela Universidade do Estado da Bahia. Especialista em Supervisão Escolar e licenciada em Pedagogia pela Universidade Estadual de Feira de Santana (UEFS). Analista de Sistemas da Universidade Estadual de Feira de Santana (UEFS). Colaboradora no Serviço de Apoio Psicopedagógico e docente da Faculdade Anísio Teixeira em Feira de Santana. E-mail: lucianauefs@hotmail.com

Contribuições dos autores: (JLF; SDC; IBM; LRS) conceitualização, captação de recursos, supervisão, redação. 